\title{
A Graphic Method of Solving $n$ Simultaneous Linear Equations involving $n$ Unknowns
}

\author{
Bx R. F. Muirhead
}

(Read 18th March, 1908. Received, same date.)

$\S 1$.

The method here explained affords a complete solution of the problem to determine by geometric construction the values of any number of unknowns connected by an equal number of equations of the first degree. The construction consists entirely of straight lines, and can be carried out by the aid of a straight-edge and a scale; or, in its modified form, in which parallel lines are required, by these instruments along with a set-square.

$\$ 2$.

The Case of two Simultaneous Equations

$$
\begin{aligned}
& a_{1} x+b_{1} y+c_{1}=0 \\
& a_{2} x+b_{2} y+c_{2}=0 \\
& \text { a triangle } \mathrm{OXY} \text {, and } \\
& a_{1} \mathrm{OX}_{1}+c_{1} \mathrm{X}_{1} \mathrm{X}=0 \\
& a_{2} \mathrm{OX}_{2}+c_{2} \mathrm{X}_{2} \mathrm{X}=0
\end{aligned}
$$

Draw a triangle $\mathrm{OXY}$, and in OX take $X_{1}, X_{2}$, so that

Similarly, in $O Y$ take the points $Y_{1}, Y_{2}$ so that

$$
\begin{aligned}
& b_{1} \mathrm{OY}_{1}+c_{1} \mathrm{Y}_{1} \mathrm{Y}=0 \\
& b_{2} \mathrm{OY}_{2}+c_{2} \mathrm{Y}_{2} \mathrm{Y}=0
\end{aligned}
$$

Let $X_{1} Y_{1}$ meet $X_{2} Y_{2}$ in $P$

$$
\begin{array}{llllll} 
& \mathrm{YP} & \text {, } & \mathrm{OX} & , \mathrm{X}_{12} \\
& \mathrm{XP} & \text { " } & \mathrm{OY} & \text { " } & \mathrm{Y}_{12}
\end{array}
$$

Then $x=\mathrm{OX}_{12} / \mathrm{X}_{12} \mathrm{X} ; y=\mathrm{OY}_{12} / \mathrm{Y}_{12} \mathrm{Y}$ are the values which satisfy (1) and (2)

To verify that they satisfy (1) we may proceed thus :-

$$
\begin{gathered}
a_{1} \frac{\mathrm{OX}_{12}}{\mathrm{X}_{12} \mathrm{X}}+b_{1} \frac{\mathrm{OY}_{12}}{\mathrm{Y}_{12} \mathrm{Y}}+c_{1}=c_{1}\left(-\frac{\mathrm{X}_{1} \mathrm{X}}{\mathrm{OX_{1 }}} \cdot \frac{\mathrm{OX}}{\mathrm{X}_{12} \mathrm{X}}-\frac{\mathrm{Y}_{1} \mathrm{Y}}{\mathrm{OY_{1 }}} \cdot \frac{\mathrm{OY}_{12}}{\mathrm{Y}_{12} \mathrm{Y}}+1\right) \\
=c_{1}\left(-\frac{\mathrm{XP}}{\mathrm{PY}} \cdot \frac{\mathrm{Y}_{12} \mathrm{Y}_{1}}{\mathrm{Y}_{1} \mathrm{O}} \cdot \frac{\mathrm{PY} \mathrm{Y}_{12}}{\mathrm{XP}} \cdot \frac{\mathrm{YO}}{\mathrm{Y}_{12} \mathrm{Y}}-\frac{\mathrm{Y}_{1} \mathrm{Y}}{\mathrm{O \textrm {Y } _ { 1 }}} \cdot \frac{\mathrm{OY_{12 }}}{\mathrm{Y}_{12} \mathrm{Y}}+1\right)
\end{gathered}
$$


(applying Menelaus' Theorem to the transversals $\mathrm{X}_{1} \mathrm{PY}_{1}$ and $\mathrm{X}_{12} \mathrm{PY}$ of the triangle $O X Y_{12}$ )

$$
\begin{aligned}
& =c_{1}\left(-\frac{\mathrm{Y}_{12} \mathrm{Y}_{1}}{\mathrm{Y}_{1} \mathrm{O}} \cdot \frac{\mathrm{YO}}{\mathrm{Y}_{12} \mathrm{Y}}-\frac{\mathrm{Y}_{1} \mathrm{Y}}{\mathrm{OY_{1 }}} \cdot \frac{\mathrm{OY}_{12}}{\mathrm{Y}_{12} \mathrm{Y}}+1\right) \\
& =c_{1} \frac{Y_{12} Y_{1} \cdot Y O+Y Y \cdot O Y_{12}+O Y_{1} \cdot Y_{12} Y}{O Y_{1} \cdot Y_{12} Y}=0 \text {. }
\end{aligned}
$$

Similarly we can show that the same values of $x$ and $y$ satisfy (2).

The process of constructing the points $X_{19}, Y_{12}$ when the points $\mathrm{X}_{1}, \mathrm{Y}_{1}, \mathrm{X}_{2}, \mathrm{Y}_{2}$ are given on the triangle $\mathrm{OXY}$ may be called for brevity "solving $\mathrm{X}_{1} \mathrm{Y}_{1}$ and $\mathrm{X}_{2} \mathrm{Y}_{2}$ graphically, as to $x$ and $y$ ", the points $X_{12}, Y_{19}$ being called "the solution".

$\S 3$.

The Case of three Equations

$$
\begin{array}{lllll}
a_{1} x+b_{1} y+c_{1} z+d_{1}=0 & - & - & - & \text { - } \\
a_{2} x+b_{2} y+c_{2} z+d_{2}=0 & - & - & - & - \\
a_{3} x+b_{3} y+c_{3} z+d_{3}=0 & - & - & - & -
\end{array}
$$

Draw any tetrastigm $O X Y Z$, and let $X_{1}, Y_{2}, X_{3}, Y_{1}, Y_{2}, Y_{3}, Z_{1}, Z_{2}, Z_{3}$ be determined in the same way as $X_{1}, Y_{1}, X_{2}, Y_{2}$, were before; e.g. $\mathrm{X}_{1}$ in $\mathrm{OX}$ makes $a_{1} \mathrm{OX} / \mathrm{X}_{1} \mathrm{X}+d_{1}=0$ and $Z_{2}$ in $\mathrm{OZ}$ makes $c_{2} \mathrm{OZ}_{2} / \mathrm{Z}_{2} \mathrm{Z}+d_{2}=0$

Then solve

$\mathrm{X}_{1} \mathrm{Z}_{1}, \mathrm{X}_{2} \mathrm{Z}_{2}$ graphically as to $x, z$, and let $\mathrm{X}_{12}, \mathrm{Z}_{12}$ be the solution $\mathbf{X}_{1} Z_{1}, \mathbf{X}_{\mathbf{8}} \mathbf{Z}_{3} \quad$ " " " " $\quad \mathbf{X}_{13}, \mathbf{Z}_{13} \quad$ ", $\mathbf{Y}_{1} \mathbf{Z}_{11} \mathbf{Y}_{\mathbf{2}} \mathbf{Z}_{2} \quad " \quad, y, z \quad " \quad \mathbf{Y}_{12} Z_{12} \quad, \quad "$ $\mathbf{Y}_{1} Z_{1}, Y_{3} Z_{3} \quad " \quad " \quad " \quad$ " $\quad Y_{13}, Z_{13} \quad "$,

Next solve $\mathrm{X}_{12} \mathrm{Y}_{12} \mathrm{X}_{13} \mathrm{Y}_{1 s}$ graphically as to $x, y$ and let $\mathrm{X}_{123} \mathrm{Y}_{123}$ be the solution. In a similar manner, by interchanging, say $X$ and $Z$, we can determine $\mathrm{Y}_{123}, \mathrm{Z}_{123}$.

Then $x=\mathrm{OX}_{123} / \mathrm{X}_{123} \mathrm{X}, y=\mathrm{OY}_{123} / \mathrm{Y}_{123} \mathrm{Y}, z=\mathrm{OZ}_{123} / \mathrm{Z}_{123} Z$ are the values of $x, y, z$ satisfying the equations (3), (4), (5).

$\$ 4$.

The Case of $n$ Equations

The extension of the method to any number of equations will now be obvious. 
If, for example, we have worked the method up to the solution of $n-1$ simultaneous equations, then for the case of $n$ equations we first solve graphically as to $x$ and $y$ two sets of $n-1$ equations each, viz.

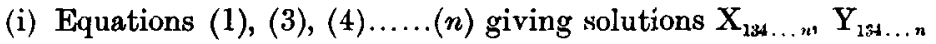

$\mathrm{X}_{124 \ldots n}, \mathrm{Y}_{124 \ldots n}$

Then solve graphically as to $x$ and $y$ the four points thus determined on $\mathrm{OX}$ and $\mathrm{OY}$, giving the solution $\mathrm{X}_{123 \ldots n,} \mathbf{Y}_{123 \ldots n}$. Then the values $x=\mathrm{OX}_{123 \ldots n} / \mathrm{X}_{123 \ldots n} \mathrm{X}, y=\mathrm{OY}_{123 \ldots n} / \mathrm{Y}_{123 \ldots n} \mathrm{Y}$, form part of the solution of the $n$ given equations; and the values of the other unknowns can be worked out in a similar manner.

It is clear that a great variety of constructions exist which can be got by interchanging pairs of letters or of suffixes, and that a limited number of these is sufficient to determine all the unknowns.

$\$ 5$.

Let us now consider the rationale of the method. It is obviously suggested by the well-known simple method of solving two simultaneous equations of the first degree by the intersection of two linear graphs. The rule for three simultaneous equations was arrived at by considering the projection upon a plane of a figure consisting of a tetrahedral coordinate system and its intersections with three planes representing the three given equations. But it is exactly parallel to the algebraic method of eliminating one unknown in two ways so as to get two equations involving only two unknowns which are then solved by eliminating successively the two remaining unknowns. And this parallel holds in the general case. It will be sufficient to point out the parallel in detail in the case of four equations with four unknowns. We have $a_{r} \frac{\mathrm{OX}}{\mathrm{X}_{r} \mathrm{X}}+e_{r}=0$, \&c. (where $r=1,2,3,4$ ) so that the $r$ th equation can be put in the form

$$
\frac{x}{\mathrm{OX}_{r} / \mathrm{X}_{r} \mathrm{X}}+\frac{y}{\mathrm{OY}_{r} / \mathrm{Y}_{r} \mathrm{Y}}+\frac{z}{\mathrm{OZ}_{r} / \mathrm{Z}_{r} \mathrm{Z}}+\frac{u}{\mathrm{OU}_{r} / \mathrm{U}_{r} \mathrm{U}}=\rho
$$


Where $\rho$ is the letter introduced to make the equations homogeneous, to which the value 1 is given, then the points $X_{12}, Y_{12}, Z_{12}$ \&c., are such that

$$
\begin{aligned}
& \frac{x}{\mathrm{OX}_{12} / \mathrm{X}_{12} \mathrm{X}}+\frac{y}{\mathrm{OY}_{12} / \mathrm{Y}_{12} \mathrm{Y}}+\frac{z}{\mathrm{OZ}_{12} / \mathrm{Z}_{12} \mathrm{Z}}=\rho \\
& \frac{x}{\mathrm{OX}_{13} / \mathrm{X}_{13} \mathrm{X}}+\frac{y}{\mathrm{OY}_{13} / \mathrm{Y}_{13} \mathrm{Y}}+\frac{z}{\mathrm{OZ}_{13} / \mathrm{Z}_{13} \mathrm{Z}}=\rho \\
& \frac{x}{\mathrm{OX}_{14} / \mathrm{X}_{14} \mathrm{X}}+\frac{y}{\mathrm{OY}_{14} / \mathrm{Y}_{14} \mathrm{Y}}+\frac{z}{\mathrm{OZ}_{14} / \mathrm{Z}_{14} \mathrm{Z}}=\rho
\end{aligned}
$$

and further

$$
\begin{aligned}
& \frac{x}{\mathrm{OX}_{123} / \mathrm{X}_{123} \bar{X}}+\frac{y}{\mathrm{OY}_{123} / \mathbf{Y}_{123} \mathrm{Y}}=\rho, \quad \frac{x}{\mathrm{OX}_{124} / \mathrm{X}_{124} \mathrm{X}}+\frac{y}{\mathrm{OY}_{124} / \mathbf{Y}_{129} \mathrm{Y}}=\rho \\
& \frac{x}{\mathrm{OX}_{1234} / \mathrm{X}_{1234} \mathrm{X}}=\rho, \frac{y}{\mathrm{O} \mathrm{Y}_{1234} / \mathrm{Y}_{1234} \mathrm{Y}}=\rho
\end{aligned}
$$

$\$ 6$.

\section{Modified Construction.}

By sending the points $X Y Z$... off to infinity, while $O$ remains near, we get an extreme case of the general method. The only modifications entailed in the construction are first, that $O X_{1}$ is cut off from OX to be equal to $-\frac{c_{1}}{a_{1}}$, instead of OX being divided in that ratio, and second, that when such a pair of lines as $X_{1} Y_{1}, X_{2} Y_{2}$ intersect in $P, X_{12}$ is got by drawing through $P$ a line parallel to $O Y$, instead of passing through $Y$.

We might further modify the construction by using only two axes of reference, say $O A, O B$, and letting each step of the graphic solution be worked on these axes. This would involve the transference of some of the points from one axis to another. For instance, in $\S 2$, if $\mathrm{OX}_{1}, \mathrm{OX}_{2}, \mathrm{OX}_{3}$ were cut off from $\mathrm{OA}$ and $\mathrm{OZ}_{1}, \mathrm{OZ}_{2}, \mathrm{OZ}_{3}$ from $\mathrm{OB}$ then the points $\mathrm{X}_{12}, \mathrm{X}_{13}$ would fall on $\mathrm{OA}$; if then the same process were carried through with $Y$ instead of $X$, we should have the points $Y_{12}, Y_{13}$ also on $O A$, and they would have to be transferred to $O B$ before we could graphically solve $X_{12}, Y_{12}, X_{13}, Y_{13}$. 
$\$ 7$.

Let us now estimate the least number of lines required in addition to $\mathrm{OX}, \mathrm{OY}, \mathrm{OZ}$, sc., to find one unknown, say $x$, from $n$ simultaneous linear equations.

For $n=2$ the number is clearly $2+1=3$

For $u=3$, if we proceed as in $\$ 3$, each of the three points $Z_{1}, Z_{3}, Z_{3}$ must be joined to 2 points ( 6 lines) giving 4 intersections through which other 4 lines have to be drawn; and the final stage requires 3 more lines; so that the total for $n=3$ is 13 lines.

For $n=4$, the number of lines required in the first stage will be $4 \times 3+9$, in the second stage 13 , and in the third 3 . Total 34 .

A little consideration will show that in the general case the number of lines required to find $x$ is $3+2.5+3.7+\ldots \ldots+(n-1)(2 n-1)$, which amounts to $n(n-1)(4 n+1) / 6$, or if we include the $n$ lines of reference OX, OY, dic., the total is $n\left(4 n^{2}-3 n+5\right) / 6$.

\section{$\$ 8$.}

\section{Verification of the Method by the aid of Determinants.}

Let us take for simplicity the modified method in which $X, Y, Z$...are at infinity and (for $\S 1$ ) $O X_{1}=-\frac{c_{1}}{a_{1}} \& c$.

In $\$ 1$ the solution of (1) and (2) is given by

$$
\begin{aligned}
& x=\left|\begin{array}{l}
b_{1} c_{1} \\
b_{2} c_{2}
\end{array}\right| \div\left|\begin{array}{l}
a_{1} b_{1} \\
a_{2} b_{2}
\end{array}\right|=\left(b_{1} c_{2}\right) \div\left(a_{1} b_{2}\right) \\
& y=-\left|\begin{array}{l}
a_{1} c_{1} \\
a_{2} c_{2}
\end{array}\right| \div\left|\begin{array}{l}
a_{1} b_{1} \\
a_{2} b_{2}
\end{array}\right|=-\left(a_{1} c_{2}\right) \div\left(a_{1} b_{2}\right)
\end{aligned}
$$

Hence, in $\$ 2$, since

$$
\begin{aligned}
& \mathrm{OX}_{12}=\left(c_{1} d_{2}\right) \div\left(a_{1} c_{2}\right) \\
& \mathrm{OX}_{13}=\left(c_{1} d_{3}\right) \div\left(a_{1} c_{3}\right) \\
& \mathrm{OY}_{12}=\left(c_{1} d_{2}\right) \div\left(b_{1} c_{2}\right) \\
& \mathrm{OY}_{13}=\left(c_{1} d_{3}\right) \div\left(b_{1} c_{3}\right)
\end{aligned}
$$

the equation to $\mathrm{X}_{13} \mathrm{Y}_{12}$ is $\frac{x\left(a_{1} c_{2}\right)}{\left(c_{1} d_{2}\right)}+\frac{y\left(b_{1} c_{2}\right)}{\left(c_{1} d_{2}\right)}=1$

and that to $\mathrm{X}_{13} \mathrm{Y}_{13}$ is $\quad x\left(a_{1} c_{3}\right)+y\left(b_{1} c_{3}\right)=\left(c_{1} d_{3}\right)$

Hence

$$
\mathrm{OX}_{123}=\left|\begin{array}{l}
\left(c_{1} d_{2}\right),\left(b_{1} c_{2}\right) \\
\left(c_{1} d_{3}\right),\left(b_{1} c_{3}\right)
\end{array}\right| \div\left|\begin{array}{l}
\left(a_{1} c_{2}\right),\left(b_{1} c_{2}\right) \\
\left(a_{1} c_{3}\right),\left(b_{1} c_{3}\right)
\end{array}\right|
$$


Now, if we denote by $A_{1} A_{2} \ldots$ the co-factors of $a_{1}, a_{2} \ldots$ in the determinant $\left(a_{1} b_{2} c_{3}\right)$ the determinant after the $\div$ sign is $=-\left|\begin{array}{ll}B_{3} & A_{3} \\ B_{2} & A_{2}\end{array}\right|=-\left|\begin{array}{ll}A_{2} & B_{2} \\ A_{3} & B_{3}\end{array}\right|$ and therefore, by the theory of reciprocal determinants and their minors, is $=-c_{1}\left(a_{1} b_{2} c_{3}\right)$. Similarly, the determinant before the sign $\div=+c_{1}\left(a_{1} b_{2} c_{3}\right)=+c_{1}\left(b_{1} c_{2} d_{3}\right)$

Thus

$$
\begin{aligned}
\mathrm{OX}_{123} & =-\left(b_{1} c_{2} d_{3}\right) \div\left(a_{1} b_{2} c_{3}\right) \\
& =-\left(d_{1} b_{2} c_{3}\right) \div\left(a_{1} b_{2} c_{3}\right)
\end{aligned}
$$

which we know to be the value of $x$ got from equations (3), (4), (5).

To extend the proof, by mathematical induction, to the general case of $n$ equations, we assume $\mathrm{OX}_{123 \ldots(n-1)}=-\left(h_{1} b_{2} c_{3} \ldots g_{n-1}\right) \div\left(a_{1} b_{2} c_{3} \ldots g_{n-1}\right)$, and then, starting with $n$ equations we have

$\mathrm{OX}_{123 \ldots(n-1)}=-\left(h_{1} c_{2} d_{3} \ldots h_{n-1}\right) \div\left(a_{1} c_{2} d_{3} \ldots h_{n-1}\right)$

$\mathrm{OX}_{123 \ldots(n-2) n}=-\left(k_{1} c_{2} d_{3} \ldots g_{n-2} h_{n}\right) \div\left(a_{1} c_{2} d_{3} \ldots g_{n-2} h_{n}\right)$ and two similar results with $\mathrm{X}$ and $\mathrm{Y}, a$ and $b$ interchanged.

Then $\quad \operatorname{oX}_{1 \ldots \ldots . . n}=\left|\begin{array}{ll}-\left(k_{1} c_{2} d_{3} \ldots h_{n-1}\right), & \left(b_{1} c_{2} d_{3} \ldots h_{n-1}\right) \\ -\left(k_{1} c_{2}\right. & \left.d_{3} \ldots g_{n-2} h_{n}\right),\left(b_{1} c_{2} d_{3} \ldots g_{n-2} h_{n}\right)\end{array}\right|$

$$
\div\left|\begin{array}{ll}
\left(a_{1} c_{2} d_{3} \ldots h_{n-1}\right), & \left(b_{1} c_{2} d_{3} \ldots h_{n-1}\right) \\
\left(a_{1} c_{2} d_{3} \ldots g_{n-2} h_{n}\right), & \left(b_{1} c_{2} d_{3} \ldots g_{n-2} h_{n}\right)
\end{array}\right|
$$

The numerator $\quad=\left|\begin{array}{ll}\mathrm{B}_{n}(-1)^{n}, & \mathbf{A}_{n}(-1)^{n-1} \\ \mathbf{B}_{n-1}(-1)^{n-1}, & \mathbf{A}_{n-1}(-1)^{n}\end{array}\right|=\left|\begin{array}{ll}\mathbf{A}_{n-1} & \mathbf{B}_{n-1} \\ \mathbf{A}_{n} & \mathbf{B}_{n}\end{array}\right|$

when $A_{n}$ is the co-factor of $a_{n}$ in the determinant $\left(a_{1} b_{2} \ldots h_{n}\right)$, dc. By the theory of Reciprocal Determinants this gives us $\left(c_{1} d_{2} \ldots h_{n-2}\right) \quad\left(a_{1} b_{2} c_{3} \ldots h_{n}\right)$ similarly the denominator reduces to $-\left(c_{1} d_{2} \ldots h_{n-2}\right)\left(k_{1} b_{2} c_{3} \ldots h_{n}\right)$

Hence $\mathrm{OX}_{12 \ldots \ldots n}=-\left(k_{1} b_{2} c_{3} \ldots \ldots h_{n}\right) \div\left(a_{1} b_{2} \ldots \ldots h_{n}\right)$, which completes the proof.

$\$ 9$.

To test the practicability of the graphic method explained in this example, I worked out on an ordinary piece of squared paper, 7 inches by 9 , with very ordinary instruments, the graphic solution of the following set of four simultaneous equations.

$$
\begin{aligned}
& x+\frac{y}{3}+\frac{z}{2}+\frac{u}{2}=1 \\
& \frac{x}{2}+y+z-u=1 \\
& 2 x-2 y-2 z-\frac{u}{2}=1 \\
& -x+\frac{y}{2}-\frac{z}{3}+\frac{u}{4}=1
\end{aligned}
$$


The numerical process of solution gives $x=\frac{584}{5} \fallingdotseq 1.104$, $y=\frac{14: 77}{5}=2 \cdot 72, z=-\frac{1134}{\overline{3} 29} \fallingdotseq-2 \cdot 15, u=\frac{66}{32 y} \fallingdotseq \cdot 125$. The graphic process gave $x=1 \cdot 14, y=2 \cdot 8$, and again $x=1 \cdot 2, z=-1.95$. The axes were taken so as to divide space into octants, each of the lines $\mathrm{OX}, \mathrm{OY}, \mathrm{OZ}, \mathrm{OU}$ making an angle of $45^{\circ}$ with the one preceding it. The second value of $x$, got by solving for $x$ and $z$, is less accurate than the first value, and this is, probably, due to the fact that the points $\mathrm{X}_{124} \mathrm{Z}_{124}$ come very close together, giving an ill-conditioned determination of the line joining them. Some of the intersections lay several inches beyond the paper, and additional pieces of paper were temporarily used. This might have been avoided by using one of the well-known methods of drawing a line through a given point or in a given direction, towards a point of intersection of two lines when it lies out of reach. I did not time myself, either during the construction or during the calculation, but my impression is that the latter took more time-and certainly it would do so in the case of equations with less simple numerical coefficients. Against this possible gain there must be set the very limited degree of accuracy of the graphical method. But I believe this method may have useful applications to a good many technical problems.

[Added 18th June, 1908.] After the foregoing paper was in print, my attention was called by the Editor to a Note on the same topic by Mr F. Boulad in Vol. 7 of the 4th Series of the "Nouvelles Annales," and I find by reference to the "Encyclopædie der Math." that several papers on the subject have appeared, the most important of which seems to be that of Van den Berg (Verslagen en Mededeelingen der koninklijke Akademie van Wetenschappen, Amsterdam, 1888.) The only article on the subject I have found published in English is that by Mr F. J. Vaes in "Engineering," Vol. 66, p. 867 (1898) which explains a method differing considerably from that given above. 